\title{
Chronic Kidney Disease Is Often Unrecognized among Patients with Coronary Heart Disease: The REGARDS Cohort Study
}

\author{
William M. McClellan ${ }^{a, g}$ Britt B. Newsome ${ }^{b}$ Leslie A. McClure ${ }^{c}$ Mary Cushman $^{d}$ \\ George Howard $^{c}$ Paul Audhya ${ }^{\mathrm{e}}$ Jerome L. Abramson ${ }^{\mathrm{f}}$ David G. Warnock ${ }^{\mathrm{g}}$ \\ a Emory University School of Medicine, Renal Division, Atlanta, Ga., ${ }^{b}$ Department of Medicine, University of \\ Alabama at Birmingham, and ${ }^{C}$ Department of Biostatistics, School of Public Health, University of Alabama at \\ Birmingham, Birmingham, Ala., ${ }^{\mathrm{d}}$ Departments of Medicine and Pathology, University of Vermont College of

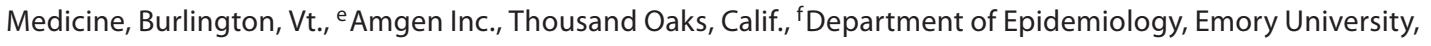 \\ Atlanta, Ga., and ${ }^{9}$ Divisions of Nephrology, Department of Medicine, University of Alabama at Birmingham, \\ Birmingham, Ala., USA
}

\section{Key Words}

Screening $\cdot$ Cardiovascular disease $\cdot$ Chronic kidney disease

\begin{abstract}
Introduction: Individuals with kidney disease are at increased risk for coronary heart disease (CHD) and CHD is associated with an increased prevalence of chronic kidney disease (CKD). Awareness of CKD may potentially influence diagnostic decisions, life-style changes and pharmacologic interventions targeted at modifiable CHD risk factors. We describe here the degree to which persons with CHD are aware of their CKD. Methods: The Reasons for Geographical and Racial Difference in Stroke (REGARDS) cohort study, a population-based sample of US residents aged 45 and older. We included in our analyses 28,112 REGARDS participants recruited as of June 2007. We estimated GFR (eGFR) using the MDRD equation, defined CKD as a GFR $<60 \mathrm{ml} / \mathrm{min} / 1.73 \mathrm{~m}^{2}$, and ascertained awareness of chronic kidney disease and coronary heart disease through self-report. We used the odds ratio to compare the association between awareness of kidney disease, as measured by GFR $<60 \mathrm{ml} / \mathrm{min} / 1.73 \mathrm{~m}^{2}$, among individuals with and without self-reported CHD by both the presence of CKD and the severity of impaired kid-
\end{abstract}

\section{KARGER}

Fax +41613061234

E-Mail karger@karger.ch

www.karger.com
(C) 2008 S. Karger AG, Basel

Accessible online at: www.karger.com/ajn ney function. Results: Coronary heart disease was reported by $3,803(14.1 \%)$ of subjects, and $11.3 \%$ of subjects had CKD by eGFR. Among all individuals with a GFR $<60 \mathrm{ml} / \mathrm{min} /$ $1.73 \mathrm{~m}^{2}, 9.6 \%$ reported having been told by a physician that they had kidney disease. Among those with CHD and CKD, $5.0 \%$ were aware of their CKD compared to $2.0 \%$ in those without CHD [OR $(95 \% \mathrm{Cl})=2.57(2.08,3.28)]$. This difference persisted after controlling for the level of kidney function [aOR $(95 \% \mathrm{Cl})=1.87(1.43,2.41)]$. Conclusion: There was a high prevalence of CKD and a low prevalence of awareness of kidney disease among older adults in the US population with or without coronary heart disease. These findings support recent recommendations that patients with cardiovascular disease be systematically screened for and educated about CKD.

Copyright $\odot 2008$ S. Karger AG, Basel

\section{Introduction}

Individuals with kidney disease are at increased risk for coronary heart disease (CHD) $[1,2]$. This increased risk occurs early in the course of kidney disease and is observed at a median glomerular filtration rate (GFR) of 
$60 \mathrm{ml} / \mathrm{min} / 1.73 \mathrm{~m}^{2}$ in patients with prevalent cardiovascular disease, at $63.9 \mathrm{ml} / \mathrm{min} / 1.73 \mathrm{~m}^{2}$ in populations at high risk for cardiovascular disease and at $72.2 \mathrm{ml} /$ $\min / 1.73 \mathrm{~m}^{2}$ in the general population [3]. A history of coronary heart disease, in turn, is associated with an increased prevalence of impaired kidney function [4] and increased risk of both incident kidney disease and progression to end-stage renal disease [5].

Recognition of kidney disease by physicians treating $\mathrm{CHD}$ is important. The presence of kidney disease should lead to lifestyle modifications and treatments targeted at risk factors for progressive kidney disease as well as $\mathrm{CHD}$ risk factors [5, 6]. Further, kidney disease should alert clinicians to reduce exposure to nephrotoxins like radiographic dye and nonsteroidal anti-inflammatory agents and to review medications for possible renal dosing modifications. Finally, the presence of kidney disease as a marker for increased risk of cardiovascular and all-cause mortality, and prolonged hospitalization, should be incorporated into clinical decision making.

While it might be expected that patients with chronic kidney disease (CKD) should be aware of and relied upon to report their kidney disease, this is often not the case [7]. Clinicians who continue to use serum creatinine to measure kidney function may misdiagnose CKD, particularly in elderly patients [8]. Current clinical practice recommendations for the detection of kidney disease recommend that screening for CKD should be based on serum creatinine-based equations to estimate the glomerular filtration rate (eGFR) and testing should be routinely included in the evaluation of individuals at-risk for or with CHD [6]. We illustrate the importance of these CKD screening recommendations by reporting a striking discrepancy between the prevalence and the awareness of CKD among individuals in the general population who have either coronary heart disease or are at high risk for CHD.

\section{Methods}

\section{Study Design and Participants}

Renal REGARDS is an ancillary study of the ongoing REasons for Geographic And Racial Differences in Stroke cohort study [9, 10]. The REGARDS cohort is a national random probability sample of individuals aged 45 years and older, $20 \%$ of whom reside in the coastal plain of North Carolina (NC), South Carolina (SC), and Georgia (GA), 30\% in the remainder of NC, SC, and GA and the southeastern states of Tennessee, Mississippi, Alabama, Louisiana and Arkansas, and 50\% in the remaining 42 contiguous states. Approximately one-half of the participants will be African-American and one-half white, and one-half male and one- half female. REGARDS recruitment began in February, 2003 and additional measures of kidney function were collected beginning in May, 2004. At the end of enrollment in 2007, a total of 30,193 participants were recruited. The sampling strategy is designed to provide sufficient statistical power to examine geographic risk factors that might contribute to the disparity in stroke incidence among African-Americans compared to whites living in the stroke belt of the Southeastern United States [9].

\section{Data}

Data collection methods have been published elsewhere [9]. Briefly, data are obtained from each participant in a telephone interview followed by a subsequent in-home examination conducted by a nurse or other health professional who was not aware of the hypotheses of this study. During the telephone interview, age, race, and sex, self-report of a previous myocardial infarction, diabetes mellitus, hypertension, and current smoking status are obtained. During a subsequent in-home examination, blood pressure is measured and blood is drawn in the fasting state with samples shipped to a central laboratory for determination of serum creatinine, and total and HDL cholesterol.

The eGFR was estimated using the abbreviated MDRD equation with serum creatinine values calibrated to the Cleveland Clinic Foundation (CCF) laboratory values used to derive the MDRD equation [8]. Even though only a single creatinine measurement for each participant was obtained at the time of the home visit, we assume that the calculated GFR represents the kidney function on a chronic basis.

In 2007 after completion of REGARDS recruitment, the REGARDS laboratory at the University of Vermont changed creatinine reagents to a method traceable to creatinine determined by isotope dilution mass spectrometry. Fifty samples were run in duplicate comparing the original method to the traceable method yielding the following calibration equation:

IDMS traceable creatinine $=-0.06+0.953 \cdot$ creatinine.

In addition, in 2007, 200 samples were sent from the REGARDS laboratory to the Cleveland Clinic for calibration resulting in the following calibration equation:

calibrated creatinine $=-0.06+0.98 \cdot$ REGARDS creatinine.

As the two equations were nearly identical, the Vermont equation was used to convert original REGARDS creatinine values to IDMS-traceable values for determination of eGFR using the formula [11]:

eGFR $=175 \cdot$ standardized creatinine $(-1.154) \cdot$ age $(-0.203) \cdot 1.212$ (if black) $\cdot 0.742$ (if female).

This approach was used to obtain the estimated GFR values for the current paper, and will be used in future publications concerning the REGARDS cohort. We defined CKD as an estimated MDRD GFR of $<60 \mathrm{ml} / \mathrm{min} / 1.73 \mathrm{~m}^{2}$.

We ascertained the presence of a personal history of kidney disease by asking participants 'Has a doctor or other health professional ever told you that you had kidney disease?' which was categorized as before as 'yes', 'no', 'don't know' and 'refused'.

We ascertained a self-reported history of coronary heart disease CHD using the following questions: (1) 'Has a doctor or any other health professional ever told you that you had a myocardial 
infarction or heart attack?' (2) 'Have you ever had a coronary artery bypass surgery, such as a graft, $\mathrm{CABG}$, or a bypass procedure on the arteries of your heart?' and (3) 'Have you ever had a an angioplasty or stenting of a coronary artery with or without placing a coil in the artery to keep it open?' All questions were scored 'yes', 'no', 'don't know' and 'refused'. We defined coronary heart disease as a yes answer to any one of these questions.

The Framingham coronary heart disease risk score, which estimates 10-year predicted risk of coronary heart disease, was calculated for each participant without a previous history myocardial infarction $[12,13]$. Risk factors included in the calculation included the following baseline characteristics: age, current smoking by self-report, blood pressure, and cholesterol. Hypertension was defined as either self-reported use of antihypertensive medications or a SBP $>140 \mathrm{~mm} \mathrm{Hg}$ or a DBP $>90 \mathrm{~mm} \mathrm{Hg}$ measured during the home examination, where SBP and DBP were the average of two measures taken in the seated position. Diabetes was defined as taking insulin or oral hypoglycemics, or either a fasting blood glucose $\geq 126 \mathrm{mg} / \mathrm{dl}$ or a nonfasting blood glucose $\geq 200 \mathrm{mg} / \mathrm{dl}$. We ascertained access to medical care by asking each participant 'Do you have a primary clinic, doctor, nurse or physician assistant who provides you with your usual medical care?' Responses were 'yes' and 'no' and all negative responses and missing answers were recorded as no medical care.

\section{Statistical Analysis}

The focus of this report was on the proportion of the population that had CKD (defined as an eGFR $<60$ and who are not currently receiving renal replacement therapy) as a function of the presence or the risk of CHD, and then subsequently the proportion of those with CKD that were aware of the condition. Means and proportions were used to describe the baseline characteristics and $t$ tests and $\chi^{2}$ tests to test differences between CKD groups. Independent associations between presence of a personal history of kidney disease and individual characteristics including CKD and CHD were assessed using multivariable logistic models that included geographic region as a covariate [14]. Analyses were conducted using SAS statistical software and Epi-Info [15, 16].

\section{Results}

We included REGARDS subjects who had completed the in-home examination $(n=30,193)$ at the end of enrollment, and who had a measured serum creatinine available by that date and who had an eGFR $\geq 10 \mathrm{ml} / \mathrm{min} /$ $1.73 \mathrm{~m}^{2}(\mathrm{n}=28,765)$. These remaining 28,889 participants had a mean (SD) age of 65.3 (9.4) years; 59.1\% were white; $45.3 \%$ were male; $58.0 \%$ had hypertension and $20.3 \%$ diabetes mellitus. A history of coronary heart disease was reported by $4,012(14.0 \%)$ of subjects, $2,397(8.3 \%)$ reported a myocardial infarction, 1,598 (5.6\%) reported previous coronary heart surgery and 2,088 (7.3\%) reported having had a percutaneous coronary artery intervention. A history of coronary heart disease was more frequent as age increased, among men and whites, and those with a history of hypertension, diabetes mellitus, and elevated cholesterol (table 1).

Chronic kidney disease was present in $11.3 \%$ of all subjects, and was present in $21.4 \%$ of individuals with $\mathrm{CHD}$ and $9.7 \%$ of those without CHD. The OR (95\% CI) for CKD among individuals with compared to those without CHD was $2.53(2.32,2.76)$. The prevalence of CKD was comparable among individuals reporting a history of myocardial infarction, coronary artery surgery and PCI (table 1). CKD prevalence increased with age, was higher among women and whites and was increased among individuals with a history of hypertension, diabetes, and elevated cholesterol (table 1).

As eGFR declined from an eGFR $\geq 60 \mathrm{ml} / \mathrm{min} / 1.73 \mathrm{~m}^{2}$ to an eGFR between 10 and $19 \mathrm{ml} / \mathrm{min} / 1.73 \mathrm{~m}^{2}$ the prevalence of coronary heart disease progressively increased from 11.0 to $39.1 \%$ (table 2). Overall, $6.7 \%$ of 3,276 individuals with CKD reported being told by a doctor or other health care professional that they had kidney disease. Further, as eGFR declined the proportion of individuals who reported a previous history of kidney disease increased from $<0.7 \%$ among those with an eGFR $\geq 60 \mathrm{ml} /$ $\mathrm{min} / 1.73 \mathrm{~m}^{2}$ to $44.6 \%$ among those with an eGFR of 10 $19 \mathrm{ml} / \mathrm{min} / 1.73 \mathrm{~m}^{2}$ (table 2).

The presence of coronary heart disease increased the degree of awareness of concurrent CKD (fig. 1). Among individuals with both $\mathrm{CHD}$ and CKD $32.0 \%$ were aware of their CKD compared to $13.7 \%$ with CKD but without $\mathrm{CHD}[\mathrm{OR}(95 \% \mathrm{CI})=2.97(2.4,3.67)]$. This difference was attenuated but persisted after controlling for the level of kidney function $[\mathrm{aOR}(95 \% \mathrm{CI})=1.76(1.37,2.28)]$.

Awareness of kidney disease among individuals with CHD and without CHD increased as kidney function decreased (table 3). The awareness of kidney disease was generally higher among those with compared to those without CHD at all levels of eGFR. For example, among individuals without CKD (eGFR $\geq 60 \mathrm{ml} / \mathrm{min} / 1.73 \mathrm{~m}^{2}$ ) $1.4 \%$ of those with and $0.6 \%$ of those without coronary heart disease reported being told they had kidney disease [OR $(95 \%$ CI $)=2.39(1.70,3.35)]($ table 3$)$.

Individuals without a previous history of coronary heart disease had a mean (SD) and median Framingham 10 -year predicted CHD risk score of $10.1 \%$ (9.7\%) and $7.0 \%$ respectively. The Framingham predicted risk was score was associated with level of kidney function, and the age-, gender- and race-adjusted score increased from a mean of 10.6 to $19.1 \%$ as kidney function decreased from an eGFR of $\geq 60$ to $10-19 \mathrm{ml} / \mathrm{min} / 1.73 \mathrm{~m}^{2}$. The prevalence of CKD varied from $7.5 \%$ among individuals in the lowest level of coronary heart disease risk to $16.5 \%$ 
Table 1. Characteristics of participants

\begin{tabular}{|c|c|c|c|c|c|}
\hline \multirow[t]{2}{*}{ Characteristics } & \multirow[t]{2}{*}{ n (\%) } & \multicolumn{2}{|l|}{ CHD } & \multicolumn{2}{|l|}{ CKD } \\
\hline & & $\begin{array}{l}\% \text { total } \\
\text { with } \mathrm{CHD}\end{array}$ & $\begin{array}{l}\text { OR }(95 \% \text { CI }) \\
\text { for CHD }\end{array}$ & $\begin{array}{l}\mathrm{n}(\%) \text { of total } \\
\text { with CKD }\end{array}$ & $\begin{array}{l}\text { OR }(95 \% \text { CI }) \\
\text { for CKD }\end{array}$ \\
\hline Total & 28,765 & 14.0 & & $3,276(11.3)$ & \\
\hline \multicolumn{6}{|l|}{ Age } \\
\hline $45-54$ years & $3,397(12.5)$ & 5.2 & ref. & $122(3.4)$ & ref. \\
\hline $55-65$ years & $11,008(38.3)$ & 10.3 & $2.06(1.78,2.42)$ & $726(6.6)$ & $2.02(1.66,2.46)$ \\
\hline $65-74$ years & $9,245(32.2)$ & 17.0 & $3.71(3.16,4.34)$ & $1,191(12.8)$ & $4.20(3.46,5.09)$ \\
\hline $75-84$ years & $4,363(15.2)$ & 22.5 & $5.23(4.44,6.17)$ & $1,035(23.7)$ & $8.91(7.33,10.83)$ \\
\hline$\geq 85$ years & $556(1.9)$ & 25.7 & $6.16(4.83,7.86)$ & $202(36.1)$ & $15.92(12.37,20.5)$ \\
\hline \multicolumn{6}{|l|}{ Gender } \\
\hline Male & $13,038(45.3)$ & 20.2 & $2.56(2.38,2.74)$ & $1,874(11.8)$ & $0.89(0.83,0.96)$ \\
\hline Female & $15,727(54.7)$ & 8.9 & ref. & $1,402(10.8)$ & ref. \\
\hline \multicolumn{6}{|l|}{ Race } \\
\hline Black & 11,755 (40.9) & 11.5 & $0.70(0.65,0.75)$ & $1,243(10.6)$ & $0.88(0.81,0.94)$ \\
\hline White & $17,008(59.1)$ & 15.6 & ref. & $2,033(11.9)$ & ref. \\
\hline Hypertension* & $16,588(58.0)$ & 17.6 & $2.18(2.02,2.34)$ & $2,580(15.5)$ & $3.08(2.82,3.36)$ \\
\hline Diabetes* & $5,987(20.3)$ & 22.7 & $2.24(2.08,2.41)$ & $1,085(18.1)$ & $2.08(1.92,2.25)$ \\
\hline Elevated cholesterol* & $14,937(52.4)$ & 20.0 & $3.10(2.87,3.45)$ & $1,980(13.2)$ & $1.32(1.26,1.38)$ \\
\hline $\mathrm{CHD}^{*}$ & $4,012(14.0)$ & & & $860(21.4)$ & $2.52(2.31,2.75)$ \\
\hline $\mathrm{MI}^{*}$ & $2,397(8.3)$ & & & $514(21.4)$ & $2.34(2.10,2.60)$ \\
\hline $\mathrm{CABG}^{*}$ & $1,598(5.6)$ & & & $399(24.9)$ & $2.79(2.48,3.15)$ \\
\hline $\mathrm{PCI}^{*}$ & $2,088(7.3)$ & & & $418(19.9)$ & $2.09(1.86,2.43)$ \\
\hline
\end{tabular}

* Reference group individuals without the condition.

Table 2. Prevalence of CHD by level of kidney function

\begin{tabular}{lrrlr}
\hline eGFR & CHD+, n (\%) & CHD-, n (\%) & OR (95\% CI) & $\begin{array}{l}\text { \% reporting history } \\
\text { of kidney disease }\end{array}$ \\
\hline$\geq 60 \mathrm{ml} / \mathrm{min} / 1.73 \mathrm{~m}^{2}$ & $3,161(12.3)$ & $22,542(87.7)$ & ref. & 0.57 \\
$59-50 \mathrm{ml} / \mathrm{min} / 1.73 \mathrm{~m}^{2}$ & $392(23.1)$ & $1,304(76.9)$ & $2.12(1.89,2.39)$ & 3.2 \\
$49-40 \mathrm{ml} / \mathrm{min} / 1.73 \mathrm{~m}^{2}$ & $255(27.8)$ & $664(72.5)$ & $2.74(2.35,3.18)$ & 5.1 \\
$39-30 \mathrm{ml} / \mathrm{min} / 1.73 \mathrm{~m}^{2}$ & $129(30.4)$ & $295(69.6)$ & $3.08(2.49,3.81)$ & 11.3 \\
$29-20 \mathrm{ml} / \mathrm{min} / 1.73 \mathrm{~m}^{2}$ & $60(34.9)$ & $112(65.1)$ & $3.86(2.81,5.30)$ & 24.4 \\
$19-10 \mathrm{ml} / \mathrm{min} / 1.73 \mathrm{~m}^{2}$ & $24(36.9)$ & $41(65.1)$ & $4.25(1.89,7.06)$ & 44.6 \\
\hline
\end{tabular}

among those in the highest Framingham risk level and $21.4 \%$ of individuals with previous history of coronary heart disease (table 4). The proportion of individuals with CKD who were aware of their CKD varied slightly over levels of the Framingham coronary heart disease risk score, ranging from $5.4 \%$ of those with a 10 -year predicted CHD risk of less than $5 \%$, to $6.4 \%$ of those with a risk greater than $20 \%(\mathrm{p}=0.0036)$ (table 4$)$.

Awareness of Kidney Disease among Individuals with CHD
The age-, gender- and race-adjusted mean uncalibrated serum creatinine ranged across levels of 10-year CHD risk from 1.01 to $1.04 \mathrm{mg} / \mathrm{dl}$ and was $1.11 \mathrm{mg} / \mathrm{dl}$ for individuals with prevalent CHD (table 4). The mean calibrated serum creatinine, adjusted for age, race and gender, ranged across levels of 10-year CHD risk from 0.90 to 0.93 $\mathrm{mg} / \mathrm{dl}$ and was $0.99 \mathrm{mg} / \mathrm{dl}$ for individuals with prevalent CHD (table 4).

Am J Nephrol 2009;29:10-17 


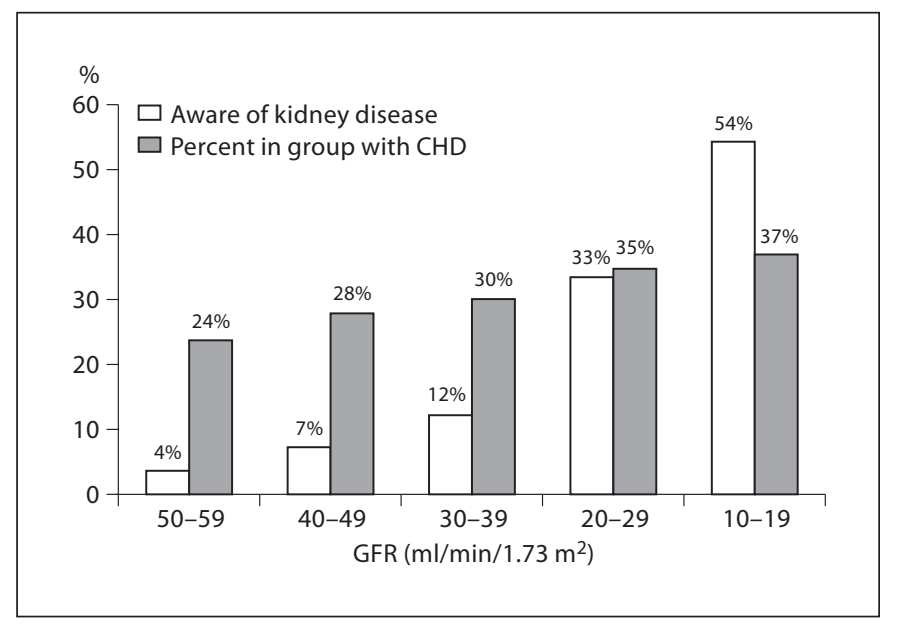

Fig. 1. Prevalence of $\mathrm{CHD}$ and awareness of CKD among individuals with CHD by level of GFR.
Table 3. Prevalence of awareness of kidney disease by level of kidney function and presence of a history of CHD, and odds of awareness of CKD comparing those with versus without CHD

\begin{tabular}{llll}
\hline eGFR & $\begin{array}{l}\mathrm{n} \text { (\%) reporting } \\
\text { history of CKD }\end{array}$ & $\begin{array}{l}\text { OR for aware- } \\
\text { ness of CKD* }\end{array}$ \\
\cline { 2 - 3 } & CHD+ & CHD- & \\
\hline$\geq 60 \mathrm{ml} / \mathrm{min} / 1.73 \mathrm{~m}^{2}$ & $45(1.4)$ & $135(0.6)$ & $2.39(1.70,3.35)$ \\
$59-50 \mathrm{ml} / \mathrm{min} / 1.73 \mathrm{~m}^{2}$ & $15(3.87)$ & $39(3.0)$ & $1.29(0.7,2.36)$ \\
$49-40 \mathrm{ml} / \mathrm{min} / 1.73 \mathrm{~m}^{2}$ & $19(7.4)$ & $28(4.2)$ & $1.87(1.01,3.34)$ \\
$39-30 \mathrm{ml} / \mathrm{min} / 1.73 \mathrm{~m}^{2}$ & $16(12.4)$ & $32(10.8)$ & $1.16(0.61,2.21)$ \\
$29-20 \mathrm{ml} / \mathrm{min} / 1.73 \mathrm{~m}^{2}$ & $20(33.3)$ & $22(19.6)$ & $2.04(1.01,4.16)$ \\
$19-10 \mathrm{ml} / \mathrm{min} / 1.73 \mathrm{~m}^{2}$ & $13(44.8)$ & $16(39.0)$ & $1.84(0.67,5.11)$
\end{tabular}

* Reference group was individuals without CHD.

Table 4. Characteristics of kidney function and awareness of kidney disease by 10 -year predicted risk of CHD

\begin{tabular}{lllllll}
\hline $\begin{array}{l}\text { Framingham } \\
\text { risk score }\end{array}$ & $\begin{array}{l}\% \\
(\mathrm{n}=28,889)\end{array}$ & $\begin{array}{l}\text { Serum creati- } \\
\text { nine*, mg/dl }\end{array}$ & $\begin{array}{l}\text { Calibrated serum } \\
\text { creatinine*, g/dl }\end{array}$ & $\begin{array}{l}\text { \% CKD } \\
(\mathrm{eGFR}<60)\end{array}$ & $\begin{array}{l}\text { Mean eGFR* } \\
\mathrm{ml} / \mathrm{min} / 1.73 \mathrm{~m}^{2}\end{array}$ & $\begin{array}{l}\text { \% reporting history } \\
\text { of kidney disease }\end{array}$ \\
\hline$<5.0 \%$ & 37.5 & 1.04 & 0.92 & 7.5 & 85.7 & 5.39 \\
$5.0-10 \%$ & 19.5 & 1.01 & 0.91 & 9.2 & 87.1 & 4.84 \\
$10.1-15 \%$ & 11.1 & 1.02 & 0.92 & 10.6 & 86.3 & 6.38 \\
$15.1-20 \%$ & 6.4 & 1.03 & 0.93 & 13.1 & 86.5 & 6.22 \\
$>20 \%$ & 10.4 & 1.04 & 0.90 & 16.5 & 87.1 & 6.36 \\
CHD & 18.1 & 1.11 & 0.99 & 21.4 & 82.0 & 9.65 \\
\hline
\end{tabular}

* Adjusted for age, gender and race. ${ }^{a}$ Among individuals with CKD (p for trend $<0.0001$ ).

Access to health care was reported by $92.1 \%$ of subjects. Individuals with access to health care and who had CKD were more likely to be aware; $1.26 \%$ reported being aware that they had kidney disease. In comparison, $0.63 \%$ of those without a usual health care provider [OR $(95 \%$ $\mathrm{CI})=1.99(1.09,3.66)]$ reported that they had kidney disease. When we examined the trend in awareness among individuals with CKD during study enrollment by 6month increments starting in January, 2003, we found no substantial changes between awareness at the start of study $(7.78 \%)$ and awareness during the most recent 6 month enrollment interval (5.11\%).

\section{Discussion}

Our main observations are that individuals in the US population with CHD have a high prevalence of CKD as determined by a low eGFR and these individuals are largely unaware of their kidney disease. Further, among those without CHD, the prevalence of CKD increased as the Framingham CHD risk score increased, while awareness of existing kidney disease remained quite low in all CHD risk groups. Mean serum creatinine levels were normal and did not vary across levels of Framingham risk groups and the majority of individuals with CHD or at high risk for CHD had serum creatinine values that were clinically considered normal. Finally, individuals who had a health care provider or health insurance did 
not substantially differ in their level of awareness from those without access to healthcare.

Our observations were not unexpected. Previous reports from the Third National Health and Examination Survey (NHANES III) found that prior to $2001 \mathrm{few}$ individuals with prevalent kidney disease in the US population were aware of their condition [7]. NHANES III asked participants 'Have you ever been told by a doctor or other health professional that you had weak or failing kidneys (excluding kidney stones, bladder infections, or incontinence)?' Among individuals with moderately severe CKD (eGFR of 30-59), 8.2\% were aware of a diagnosis of kidney disease. Individuals in the REGARDS cohort with CKD, with or without coronary disease, were somewhat $(6.7 \%)$ less aware of their CKD. This difference may reflect the different survey wording. It is also possible that the older REGARDS subjects had lower awareness of CKD compared to NHANES III participants, where subjects aged 20 years and older were included in the analysis. With respect to this possibility, awareness of kidney disease among REGARDS participants varied substantially across age strata and was $13.93 \%$ among those aged $45-55$ years and $2.48 \%$ among those aged $75-85$ years $(\mathrm{p}<0.0001)$. The findings in this study underscore the persistence through the June of 2008 of a low degree of awareness of impaired function among individuals with kidney disease in the US population.

The high prevalence of unawareness CKD among older Americans with CHD and who are at high risk for CHD has important implications for clinicians. First, recommendations that patients at high risk for cardiovascular disease should routinely have an eGFR measured are supported by our results [6]. Further, physicians who rely on either the serum creatinine, or on the patient's self-report to identify underlying kidney disease will under-diagnose the presence of impaired kidney function [8]. Second, the presence of kidney disease should result in a number of clinical decisions specific to the management of risk of progressive kidney disease [18]. JNC VII and American Diabetes Association recommendations for blood pressure management of patients with kidney disease call for a lower target goal of 130/80 $\mathrm{mm} \mathrm{Hg}$ and for strong consideration to using either an angiotensinconverting enzyme inhibitor or receptor blocker $[19,20]$. Dietary protein should be limited to the recommended daily allowance of $0.8 \mathrm{~g} / \mathrm{kg} / \mathrm{day}[20,21]$. Attention should also be paid to avoiding nephrotoxic medications and judicious use of radiographic contrast agents [22]. Patients should be assessed for the presence of anemia and renal bone disease and, if present, care for these conditions initiated $[23,24]$.

Third, the low level of reported awareness of impaired kidney function emphasizes the need to screen, evaluate and communicate the diagnosis of CKD to the patient. Patients should be educated as to the importance of blood pressure control, dietary and medication adherence, and avoidance of nephrotoxins as measures to protect remaining kidney function. It is crucial that information about kidney function be effectively communicated between referring physicians to avoid lapses in continuity of care.

Finally, it is important for clinicians diagnosing CKD to establish a plan for monitoring kidney function over time and for early referral for those individuals with progressive kidney disease. It is recommended that individuals with advanced CKD, defined as stage 4 CKD (GFR $<30 \mathrm{ml} / \mathrm{min} / 1.73 \mathrm{~m}^{2}$ ) be referred to a nephrologist as individuals with this level of kidney function have a $20 \%$ risk of needing renal replacement therapy [18].

The prevalence of an MDRD GFR of $<60 \mathrm{ml} / \mathrm{min} /$ $1.73 \mathrm{~m}^{2}$ in the REGARDS cohort is higher then that recently reported by Coresh et al. [25] from the 1999-2004 National Health and Nutrition Surveys. Since the REGARDS cohort is, by design, older than the NHANES sample, the best comparison between the two studies is based on age-specific estimates of CKD.

We have previously called attention to the unexpectedly higher prevalence of CKD in whites compared to blacks and women compared to men after accounting for age, race and gender as appropriate [26]. Similar observations have also been reported from NHANES [25]. In 1999-2004, the prevalence of CKD among non-Hispanic white men was 11.1 and $15.0 \%$ among non-Hispanic white women, while the comparable CKD prevalence of among non-Hispanic black men and women was 13.8 and 8.0\% [25]. The reasons for the unexpected increased prevalence of CKD among blacks is not fully understood but it has been speculated that the disparity is likely due to increased rates progression of impaired kidney function among blacks [27].

There are limitations to our report that should be noted. First, it is possible that that self-reported kidney disease may not accurately reflect actual information provided to participants by their health care providers. While this possibility cannot be excluded, recent reports from managed care plans suggest that CKD is largely undiagnosed in these populations as well [17]. Second, we could not validate the history of coronary disease and it is possible that some individuals were misclassified. This would not alter 
the main observation that individuals with kidney disease who perceive themselves as having coronary disease, or who are at high risk of coronary heart disease, are generally unaware of their kidney disease, and that having a health care provider does not substantially change their level of awareness. Third, we did not ascertain whether participants visited their health care providers, and cannot estimate the intensity of use of these services. However, it seems unlikely that variations in the frequency of health care use would substantially change our conclusions. It should also be noted that we restricted our analyses to individuals with decreased GFR and did not account for kidney disease defined by presence of proteinuria or other genitourinary abnormalities and otherwise normal GFR. In view of the overall low degree of awareness of CKD among those with normal GFR, it is unlikely that a broader definition of kidney disease would change the main point of our observations that individuals with $\mathrm{CHD}$ are at risk of undetected impaired kidney function.

Neither of the questions used to identify patients with $\mathrm{CKD}$ or CAD have been validated and it is possible that both conditions are subject to misclassification. However, in view of the low levels of reported awareness of CKD, even in the lowest levels of GFR, it is unlikely that correction of misclassification would reduce the probability that many patients with CHD have undetected CKD.

The major strengths of our observations are that they were derived from a random sample of the older US population and, although our sample was geographically weighed toward populations in the Southeastern United States, we had sufficient power to provide representative estimates for the entire population. Finally, our observations included subjects enrolled in REGARDS up to June, 2007, and thus provide current information relevant to the detection and awareness of CKD among these highrisk patients.

In summary, older Americans are at a high risk of kidney disease and this risk increases as the risk of CHD increases. Awareness of CKD among all older Americans and among those with CHD or high risk of CHD is quite low. Routine use of serum creatinine-based estimates of kidney function, but not serum creatinine level, should be used to screen for CKD and, if CKD is present, clinicians should implement measures to delay the progression of kidney disease and to ensure appropriate referral for those individuals who are likely to require renal replacement therapy. Finally, the optimal recommendations for life-style modifications and pharmacologic interventions to minimize CHD must be cognizant of CKD in the patient population. Direct screening for CKD by eGFR measurements will be far more specific than relying on patients self-reported history of CKD.

\section{Acknowledgments}

This research project is supported by a cooperative agreement U01 NS041588 from the National Institute of Neurological Disorders and Stroke, National Institutes of Health, Department of Health and Human Services. Additional funding was provided by an investigator-initiated grant-in-aid from Amgen Inc. Amgen did not have any role in the design and conduct of the study, the collection, management, analysis, and interpretation of the data, or the preparation or approval of the manuscript. The manuscript was sent to Amgen for review prior to submission for publication.

The authors acknowledge the participating investigators and institutions: University of Alabama at Birmingham, Birmingham, Alabama (Study PI, Data Coordinating Center, Survey Research Unit): George Howard, Leslie McClure, Virginia Howard, Libby Wagner, Virginia Wadley, Rodney Go, Ella Temple, Margaret Stewart); University of Vermont (Central Laboratory): Mary Cushman; Wake Forest University Medical Center (ECG Reading Center): Ron Prineas; Alabama Neurological Institute (Stroke Validation Center, Medical Monitoring): Camilo Gomez, David Rhodes, Susanna Bowling; University of Arkansas for Medical Sciences (Survey Research): LeaVonne Pulley; University of Cincinnati (Clinical Neuroepidemiology): Brett Kissela, Dawn Kleindorfer; Examination Management Services Incorporated (InHome Visits): Andra Graham; National Institute of Neurological Disorders and Stroke, National Institutes of Health (funding agency): Claudia Moy.

\section{References}

1 Vanholder R, Massy Z, Argiles A, Spasovski G, Verbeke F, Lameire N, European Uremic Toxin Work Group: Chronic kidney disease as cause of cardiovascular morbidity and mortality. Nephrol Dial Transplant 2005;20: 1048-1056

2 Levey AS, Beto JA, Coronado BE, Eknoyan G, Foley RN, Kasiske BL, Klag MJ, Mailloux LU, Manske CL, Meyer KB, Parfrey PS, Pfef- fer MA, Wenger NK, Wilson PW, Wright JT Jr: Controlling the epidemic of cardiovascular disease in chronic renal disease: what do we know? What do we need to learn? Where do we go from here? National Kidney Foundation Task Force on Cardiovascular Disease. Am J Kidney Dis 1998;32:853-906.

3 Manjunath G, Tighiouart H, Coresh J, Macleod B, Salem DN, Griffith JL, Levey AS, Sar- nak MJ: Level of kidney function as a risk factor for cardiovascular outcomes in the elderly. Kidney Int 2003;63:1121-1129.

-4 Manjunath G, Tighiouart H, Ibrahim H, MacLeod B, Salem DN, Griffith JL, Coresh J, Levey AS, Sarnak MJ: Level of kidney function as a risk factor for atherosclerotic cardiovascular outcomes in the community. J Am Coll Cardiol 2003;41:47-55. 
5 Sarnak MJ, Levey AS, Schoolwerth AC, Coresh J, Culleton B, Hamm LL, McCullough PA, Kasiske BL, Kelepouris E, Klag MJ, Parfrey P, Pfeffer M, Raij L, Spinosa DJ, Wilson PW, American Heart Association Councils on Kidney in Cardiovascular Disease, High Blood Pressure Research, Clinical Cardiology, and Epidemiology and Prevention: Kidney disease as a risk factor for development of cardiovascular disease: a statement from the American Heart Association Councils on Kidney in Cardiovascular Disease, High Blood Pressure Research, Clinical Cardiology, and Epidemiology and Prevention. Circulation 2003;108:2154-2169.

-6 Brosius FC 3rd, Hostetter TH, Kelepouris E, Mitsnefes MM, Moe SM, Moore MA, Pennathur S, Smith GL, Wilson PW: Detection of chronic kidney disease in patients with or at increased risk of cardiovascular disease: a science advisory from the American Heart Association Kidney and Cardiovascular Disease Council; the Councils on High Blood Pressure Research, Cardiovascular Disease in the Young, and Epidemiology and Prevention; and the Quality of Care and Outcomes Research Interdisciplinary Working Group Developed in Collaboration with the $\mathrm{Na}$ tional Kidney Foundation. Circulation 2006; 114:1083-1087.

7 Coresh J, Byrd-Holt D, Astor BC, Briggs JP, Eggers PW, Lacher DA, Hostetter TH: Chronic kidney disease awareness, prevalence, and trends among US adults, 1999 to 2000. J Am Soc Nephrol 2005;16:180-188.

-8 Stevens LA, Coresh J, Greene T, Levey AS: Assessing kidney function - measured and estimated glomerular filtration rate. $\mathrm{N}$ Engl J Med 2006;354:2473-2483.

-9 Howard VJ, Cushman M, Pulley L, Gomez CR, Go RC, Prineas RJ, Graham A, Moy CS, Howard G: The Reasons for Geographic and Racial Differences in Stroke Study: objectives and design. Neuroepidemiology 2005; 25:135-143.
10 Warnock DG, McClellan W, McClure LA, Newsome B, Campbell RC, Audhya P, Cushman M, Howard VJ, Howard G: Prevalence of chronic kidney disease and anemia among participants in the Reasons for Geographic and RacialDifferences in Stroke(REGARDS) Cohort Study: baseline results. Kidney Int 2005;68:1427-1431.

11 Levey AS, Coresh J, Greene T, Marsh J, Stevens LA, Kusek JW, Van Lente F: Expressing the Modification of Diet in Renal Disease Study equation for estimating glomerular filtration rate with standardized serum creatinine values. Clin Chem 2007;53:766-772.

12 Wilson PWF, D’Agostino RB, Levy D, Belanger AM, Silbershatz H, Kannel WB: Prediction of coronary heart disease using risk factor categories. Circulation 1998;97:18371847.

13 D’Agostino S, Grundy S, Sullivan LM, Wilson P, CHD Risk Prediction Group: Validation of the Framingham Coronary Heart Disease Prediction Scores: results of a Multiple Ethnic Groups Investigation. JAMA 2001;286:180-187.

14 Kleinbaum DG, Klein M: Logistic Regression: A Self-Learning Text, ed 2. New York, Springer, 2002.

15 SAS Institute Inc., Version 8. Cary, SAS Institute Inc, 2000.

16 CDC: Epi Info 2002. Database and statistics software for public health professionals [http://www.cdc.gov/epiinfo/]. July 2002 Edition CDC 2002.

17 Stevens LA, Fares G, Fleming J, Martin D, Murthy K, Qiu J, Stark PC, Uhlig K, Van Lente F, Levey AS: Low rates of testing and diagnostic codes usage in a commercial clinical laboratory: evidence for lack of physician awareness of chronic kidney disease. J Am Soc Nephrol 2005; 16:2439-2448.

18 National Kidney Foundation: K/DOQI clinical practice guidelines for chronic kidney disease: evaluation, classification, and stratification. Am J Kidney Dis 2002;39(2 suppl 1):S1-S266.
19 Chobanian AV, Bakris GL, Black HR, et al: National Heart, Lung and Blood Institute Joint National Committee on Prevention, Detection, Evaluation and Treatment of High Blood Pressure; National High Blood Pressure Education Program Coordinating Committee. The Seventh Report of the Joint National Committee on Prevention, Detection, Evaluation, and Treatment of High Blood Pressure: the JNC 7 report. JAMA 2003;289:2560-2572.

20 American Diabetes Association: Nephropathy in diabetes: position statement. Diabetes Care 2004;27:S79-S83.

21 Kopple JD: National kidney foundation K/ DOQI clinical practice guidelines for nutrition in chronic renal failure. Am J Kidney Dis 2001;37(1 suppl 2):S66-S70.

-22 Solomon R, Deray G; Consensus Panel for CIN: How to prevent contrast-induced nephropathy and manage risk patients: practical recommendations. Kidney Int Suppl 2006;100:S51-S53.

23 KDOQI; National Kidney Foudnation: II. Clinical practice guidelines and clinical practice recommendations for anemia in chronic kidney disease in adults. Am J Kidney Dis 2006;47(5 suppl 3):S16-S85.

24 National Kidney Foundation: K/DOQI clinical practice guidelines for bone metabolism and disease in chronic kidney disease. Am J Kidney Dis 2003;42(4 suppl 3):S1-S201.

25 Coresh J, Selvin E, Stevens LA, Manzi J, Kusek JW, Eggers P, Van Lente F, Levey AS: Prevalence of chronic kidney disease in the United States. JAMA 2007;298:2038-2047.

26 McClellan W, Warnock DG, McClure L, Campbell RC, Newsome BB, Howard V, Cushman M, Howard G: Racial differences in the prevalence of chronic kidney disease among participants in the Reasons for Geographic and Racial Differences in Stroke (REGARDS) Cohort Study. J Am Soc Nephrol 2006;17:1710-1715.

$\checkmark 27$ Hsu CY, Lin F, Vittinghoff E, Shlipak MG: Racial differences in the progression from chronic renal insufficiency to end-stage renal disease in the United States. J Am Soc Nephrol 2003;14:2902-2907. 